\title{
The Intellectual Structure of Business Analytics: 2002-2019
}

\author{
Hyaejung Lim, Chang-Kyo Suh \\ School of Business Administration \\ Kyungpook National University \\ 80 Daehak-ro, Buk-gu, Daegu, 41566 \\ Republic of Korea \\ limhyaejung@gmail.com, ck@knu.ac.kr
}

\begin{abstract}
This paper identifies the intellectual structure of business analytics using document cocitation analysis (DCA) and author co-citation analysis (ACA). A total of 333 research documents and 17,917 references from the Web of Science were collected. A total of 15 key documents and nine clusters were extracted from the analysis to clarify sub-areas. Furthermore, burst detection and timeline analysis were conducted to gain a better understanding of the overall trends in business analytics. The main implication of the research results is in its ability to provide the state of past and present standards to practitioners and to suggest further research into business analytics to researchers.
\end{abstract}

Key-Words: - Business Analytics, Intellectual Structure, CiteSpace, Document Co-citation Analysis, Author Co-citation Analysis

\section{INTRODUCTION}

Upon the opening of the digital era, data collection from a variety of fields became a relatively easier task. The amount of data available also became enormously large, resulting in so-called 'big data.' The uses for big data are potentially infinite and the importance of 'business analytics' has rapidly increased. Business analytics enables big data to be used most effectively and efficiently. It detects meaningful patterns in data and interprets these patterns to provide an organization better information for decision-making. This process can also provide an organization's prediction system with better insight.

As organizations applied prediction functions based on the statistics of analyzed data, the increased usage of business analytics became inevitable and research on business analytics increased steadily. However, despite the accumulation of numerous amounts of research on business analytics over the last two decades, a precise concept of its intellectual structure has not yet been established. This leads to difficulty in understanding its sub-areas and trends in the research field. 'Intellectual structure' means that there is an invisible structure that emerges from research that builds and systematizes one concept.
Through the analysis of the intellectual structure of business analytics, we can identify the current state of the field and simultaneously provide detailed subject areas and directions in which the field might proceed in the future.

This paper is comprised of five sections. The second section reviews previous research papers that analyzed the intellectual structures of various fields and used CiteSpace to visualize intellectual structures. The third section discusses how to analyze the intellectual structure of business analytics. In Section 4, the results of the analysis are provided and interpreted. Lastly, Section 5 summarizes the analysis and discusses future research directions in business analytics as the conclusion.

\section{LITERATURE REVIEW}

The most common metrics used to measure intellectual structures are document co-citation analysis (DCA) and author co-citation analysis (ACA). In 1981, White and Griffith [21] first applied ACA to their research in order to identify its intellectual structure. Since their pioneering research, various fields of research have used this method. White and Griffith [21] identified five subareas and 39 major authors in the information field. The five sub-areas identified are science communication, statistics, general, information search, and leadership. Acedo and Casillas [1] applied ACA to the international management field in 2005. Based on 583 documents published between 1997 and 2000, researchers concluded that there were eight sub-areas, including joint ventures, economic approaches, and process approaches. Shiau et al. [17] identified a total of 13 sub-areas by applying ACA in the management information systems field. The sub-areas are applying techniques, information techniques, company performance, competitive advantage, and company structure. 
In 2004, Chen [5] introduced CiteSpace and applied this tool to the knowledge domain visualization field. Based on 'Institute for Scientific Information' data collected between 1985 and 2003, he effectively identified changes in the knowledge domain field by using CiteSpace. Cui et al. [8] analyzed the I-model based on social commerce documents and provided the intellectual structure of the field. A total of 12,089 data were collected between the years 2005 and 2017. Cui et al. [8] identified the most influential authors and visualized the network using keywords.

Since the appearance of CiteSpace, researchers have steadily utilized the program to analyze their research more objectively and clearly, including university-industry collaborations [10], e-learning and social learning [23], ecological assets and values [15], information science [22], hospitality [14], and others.

\section{ANALYZING THE RESEARCH}

\section{A. Analysis Methods and Data Collection}

This research identifies the intellectual structure of business analytics research. To analyze the intellectual structure of business analytics research, we performed DCA and ACA. DCA maps a study based on the number of co-citations of the documents. ACA posits that if two authors are cited in one document simultaneously, then the two authors are academically related to each other [21]. These two analysis methods can identify academic study areas and sub-areas, as well as changes in trends in the domain. As the size of the data becomes larger, the results of the analysis become more detailed and meaningful.

\section{Table 1. Document Counts for Each Year}

\begin{tabular}{|c|c|c|c|c|c|}
\hline Year & $\mathbf{2 0 0 2}$ & $\mathbf{2 0 0 3}$ & $\mathbf{2 0 0 4}$ & $\mathbf{2 0 0 5}$ & $\mathbf{2 0 0 6}$ \\
\hline Document Counts & 1 & 1 & 0 & 1 & 0 \\
\hline Reference Counts & 9 & 10 & 0 & 9 & 0 \\
\hline Year & $\mathbf{2 0 0 7}$ & $\mathbf{2 0 0 8}$ & $\mathbf{2 0 0 9}$ & $\mathbf{2 0 1 0}$ & $\mathbf{2 0 1 1}$ \\
\hline Document Counts & 4 & 4 & 0 & 5 & 5 \\
\hline Reference Counts & 182 & 158 & 0 & 212 & 379 \\
\hline Year & $\mathbf{2 0 1 2}$ & $\mathbf{2 0 1 3}$ & $\mathbf{2 0 1 4}$ & $\mathbf{2 0 1 5}$ & $\mathbf{2 0 1 6}$ \\
\hline Document Counts & 8 & 8 & 23 & 41 & 43 \\
\hline Reference Counts & 403 & 252 & 1271 & 1757 & 2323 \\
\hline Year & $\mathbf{2 0 1 7}$ & $\mathbf{2 0 1 8}$ & $\mathbf{2 0 1 9}$ & & Total \\
\hline Document Counts & 50 & 67 & 72 & & $\mathbf{3 3 3}$ \\
\hline Reference Counts & 2533 & 3529 & 4890 & & $\mathbf{1 7 9 1 7}$ \\
\hline
\end{tabular}

The data used in this research were collected from the Web of Science using the keyword 'business analytics.' Among the total of 386 articles published between 2002 and 2019, 333 documents with 17,917 references were extracted as the final data. As indicated in Table 1, the number of documents increased every year since 2002 .

\section{B. Analyzing with CiteSpace}

In this research we used CiteSpace, developed by Chen [6], to analyze intellectual structure by applying DCA and ACA. CiteSpace is a java program that visualizes the network and analyzes changes in trends. When the data are inserted into CiteSpace, they appear as one network. Each node expresses a document or the author of the data and the node's size represents its centrality.

The structural analysis of the network contains the betweenness centrality, modularity $\mathrm{Q}$, and the silhouette. The betweenness centrality expresses itself as each node and connects the other nodes. If a node has more links to other nodes, the node has a higher betweenness centrality. If a node has a high betweenness centrality, the node has a high level of control of the overall network. The modularity Q, which measures how well-separated the network is, has a numerical value from 0 to 1 ; the closer it is to 1 , the better the network is. A low modularity Q means that the network cannot form a well-separated cluster. The silhouette metric, which expresses the uncertainty of the clusters, is a numerical value between -1 and 1 ; the closer it is to 1 , the more wellperforming the clustering analysis is [6].

It is also possible to detect bursts using CiteSpace. A burst is an indicator that detects a great change in the research occurring during a short time period. For example, when the terror attacks of 9/11 happened in the United States, research regarding the Oklahoma City bombing suddenly received attention. Therefore, past research that is related to the current situation becomes important for predicting the future.

\section{RESULTS OF THE ANALYSIS}

\section{A. Clustering Analysis}

To analyze the sub-research areas in business analytics, we performed clustering analysis using CiteSpace. Clustering analysis classifies data with similar characteristics by calculating similarities in distance and forming clusters from data close to each other [12]. A total of nine clusters of analysis appeared on the network as a result of the clustering analysis (see Figure 1). By default, only the top 10\% of the data are contained in the clustering analysis. 


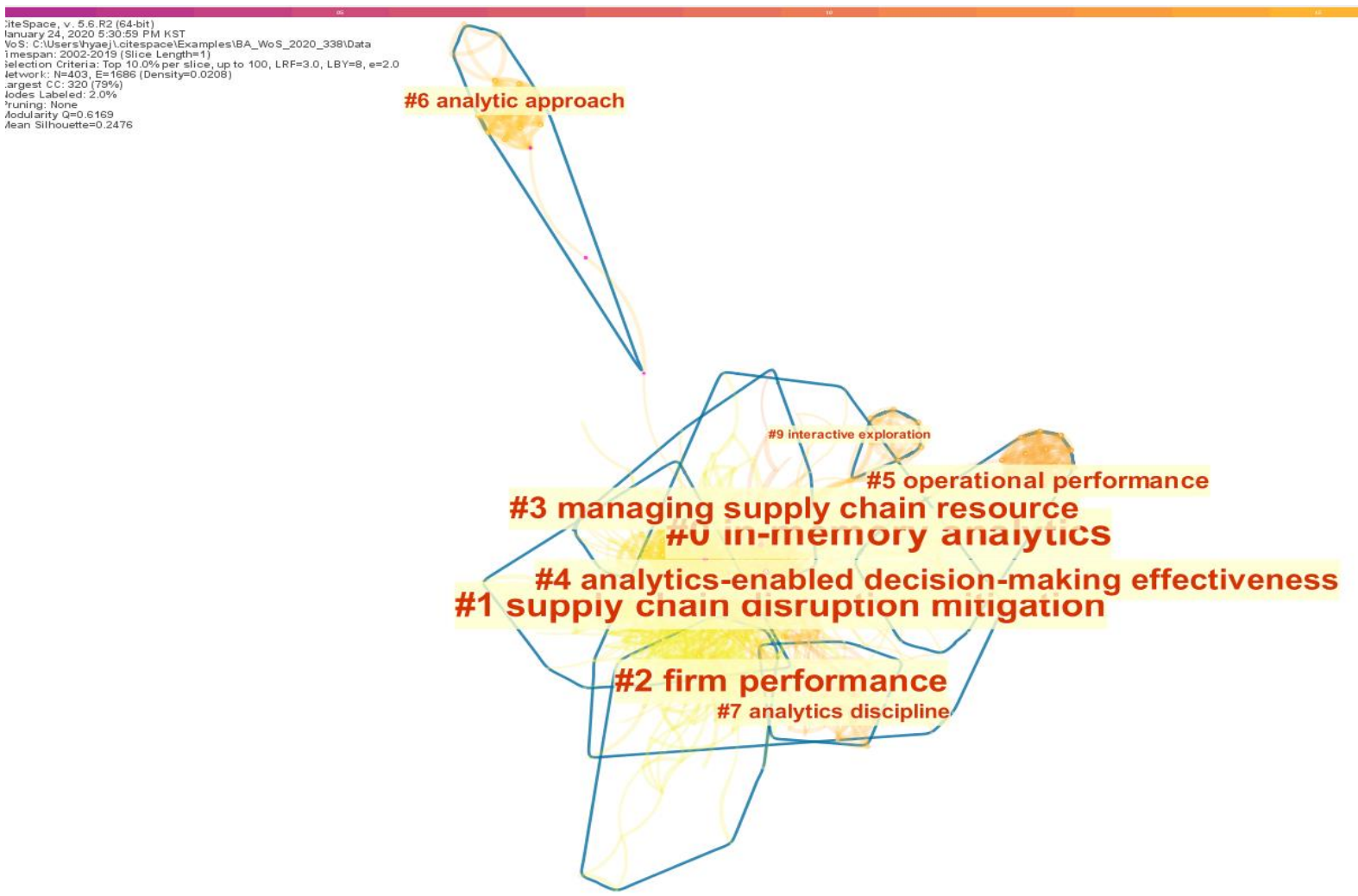

Fig 1. Business Analysis Cluster Network

The modularity Q of this research is 0.6169 , which means the structure is well enough separated. The silhouette value is 0.2476 , which means that the clusters were well divided. Numerical information about the nine clusters is summarized in Table 2. In this study, the top two clusters (Cluster \#0 and Cluster \#1), as well as Cluster \#6, are analyzed in detail (see Tables 3, 4, and 5).

Table 2. Nine Clusters of Business Analytics Research

\begin{tabular}{|c|c|c|c|c|}
\hline cluster ID & Size & Silhouette & Mean(Year) & Label(log-likelihood ratio) \\
\hline 0 & 62 & 0.443 & 2013 & In-memory Analytics \\
\hline 1 & 54 & 0.695 & 2016 & Supply Chain Disruption Mitigation \\
\hline 2 & 47 & 0.783 & 2015 & Firm Performance \\
\hline 3 & 44 & 0.843 & 2014 & Managing Supply Chain Resource \\
\hline 4 & 41 & 0.769 & 2013 & Analytics-enabled Decision-making Effectiveness \\
\hline 5 & 26 & 0.912 & 2011 & Operational Performance \\
\hline 6 & 19 & 0.986 & 2011 & Analytic Approach \\
\hline 7 & 19 & 0.915 & 2011 & Analytics Discipline \\
\hline 9 & 8 & 0.988 & 2009 & Interactive Exploration \\
\hline
\end{tabular}

\section{A.1. Cluster \#0}

Cluster \#0 (In-Memory Analytics) is the largest cluster with 62 references. The five selected citing articles cited $10-22 \%$ of these references. "Practitioners understanding of big data and its applications in supply chain management" [4] has the highest citation coverage and the most cited article is "Business intelligence and analytics: From big data to big impact" [7]. The 'In-Memory Analytics' research proposes the general framework of business intelligence (BI) research, distinguishes the major issues, and suggests the usage of data to apply business analytics properly to the management system (see Table 3).

\section{A.2. Cluster \#1}

Cluster \#1 (Supply Chain Disruption Mitigation) is composed of 54 references. The five selected citing articles cited $14-31 \%$ of these references. "The role of business analytics capabilities in bolstering firms' agility and performance" [3] has the highest citation coverage and the most cited article is "How to improve firm performance using big data analytics capability and business strategy alignment?" [2]. 'Supply Chain Disruption Mitigation' research exhibits the limitations of resource-based management and its business analytics suggests a way to lower the odds of business analytics application's failure, especially in supply chain management (see Table 4).

\section{A.3. Cluster \#6}

Although Cluster \#6 (Analytic Approach) is a relatively small cluster with only 19 references, it has more documents with a high betweenness centrality than do other clusters. The five selected citing articles cited $3-14 \%$ of the references. "A data analytic approach to forecasting daily stock returns in an emerging market" [16] has the highest citation coverage and the most cited article is "Data mining: 
Concepts and techniques" [11]. Cluster \#6 explains how the raw data should be converted into usable and meaningful data. Moreover, it exhibits the best way to effectively deal with converted data. The research is based on machine learning and data mining and focuses mainly on predictive analysis.

Table 3. Cluster \#0 - In-Memory Analytics

\begin{tabular}{|c|c|c|c|c|c|c|c|c|c|}
\hline \multicolumn{10}{|c|}{ Cluster \#0 In-Memory Analytics } \\
\hline \multicolumn{5}{|c|}{ Cited References } & \multicolumn{5}{|c|}{ Citing Articles } \\
\hline Cites & Author & Year & Title & Journal & Coverage $(\%)$ & Author & Year & Title & Journal \\
\hline 74 & Chen, $\mathrm{HC}$ & 2012 & $\begin{array}{l}\text { Business intelligence and analytics: } \\
\text { From big data to big impact. }\end{array}$ & MIS Quarterly & 22 & Brinch, M & 2018 & $\begin{array}{l}\text { Practitioners understanding of big data and } \\
\text { its applications in supply chain management. }\end{array}$ & $\begin{array}{l}\text { Int J Logis } \\
\text { Manage }\end{array}$ \\
\hline 42 & McAfee, A & 2012 & Big data: the management revolution. & Harvard Review & 18 & Akter, S & 2019 & $\begin{array}{l}\text { Analytics-based decision-making for service systems: } \\
\text { a qualitative study and agenda for future research. }\end{array}$ & Int J Inf Manage \\
\hline 38 & Lavalle, $S$ & 2011 & Big data, analytics and the path from insights to value. & MIT Sloan & 16 & Mitri, M & 2015 & $\begin{array}{l}\text { Toward a model undergraduate curriculum for the } \\
\text { emerging business intelligence and analytics discipline. }\end{array}$ & $\begin{array}{c}\text { Comm the Assoc } \\
\text { Infor Syst }\end{array}$ \\
\hline 38 & Manyika, J & 2011 & $\begin{array}{l}\text { Big data: The next frontier for innovation, } \\
\text { competition, and productivity. }\end{array}$ & Big Data & 13 & Akter, S & 2016 & $\begin{array}{l}\text { Big data analytics in e-commerce: } \\
\text { a systematic review and agenda for future research. }\end{array}$ & Electronic Markets \\
\hline 29 & Sharma R & 2014 & $\begin{array}{l}\text { Transforming decision-making processes: a research } \\
\text { agenda for understanding the impact of business } \\
\text { analytics on organisations. }\end{array}$ & $\begin{array}{l}\text { Eur J } \\
\text { Information } \\
\text { Systems }\end{array}$ & 10 & Phillips-Wren, G & 2015 & $\begin{array}{l}\text { Business analytics in the context of } \\
\text { big data: a roadmap for research. }\end{array}$ & $\begin{array}{c}\text { Comm the Assoc } \\
\text { Infor Syst }\end{array}$ \\
\hline
\end{tabular}

Table 4. Cluster \#1 - Supply Chain Disruption Mitigation

\begin{tabular}{|c|c|c|c|c|c|c|c|c|c|}
\hline \multicolumn{10}{|c|}{ Cluster \#1 Supply Chain Disruption Mitigation } \\
\hline \multicolumn{5}{|c|}{ Cited References } & \multicolumn{5}{|c|}{ Citing Articles } \\
\hline Cites & Author & Year & Title & Journal & Coverage $(\%)$ & Author & Year & Title & Journal \\
\hline 12 & Akter, $S$ & 2016 & $\begin{array}{c}\text { How to improve firm performance using big data analytics } \\
\text { capability and business strategy alignment? }\end{array}$ & Int J Prod Econ & 31 & Ashrafi, A & 2019 & $\begin{array}{l}\text { The role of business analytics capabilities in bolstering } \\
\text { firms' agility and performance. }\end{array}$ & Int J Inf Manage \\
\hline 10 & Gupta, M & 2016 & Toward the development of a big data analytics capability & $\begin{array}{c}\text { Infor } \\
\text { Manage-Amster }\end{array}$ & 19 & Brinch, M & 2018 & $\begin{array}{l}\text { Practitioners understanding of big data and its } \\
\text { applications in supply chain management. }\end{array}$ & $\begin{array}{l}\text { Int J Logis } \\
\text { Manage }\end{array}$ \\
\hline 9 & Gunasekaran, A & 2017 & $\begin{array}{l}\text { Big data and predictive analytics for supply chain } \\
\text { and organizational performance. }\end{array}$ & J Bus Res & 15 & Singh, $N$ & 2019 & $\begin{array}{l}\text { Building supply chain risk resilience: role of big data } \\
\text { analytics in supply chain disruption mitigation. }\end{array}$ & $\begin{array}{c}\text { Benchmarking-Int } \\
\mathrm{J}\end{array}$ \\
\hline 7 & Popovic, A & 2018 & $\begin{array}{l}\text { The impact of big data analytics on firms' } \\
\text { high value business performance. }\end{array}$ & Infor Syst Front & 14 & Akter, $S$ & 2019 & $\begin{array}{l}\text { Analytics-based decision-making for service systems: a } \\
\text { qualitative study and agenda for future research. }\end{array}$ & Int J Inf Manage \\
\hline 7 & Corte-Real, N & 2017 & $\begin{array}{c}\text { Assessing business value of } \\
\text { Big Data Analytics in European firms. }\end{array}$ & J Bus Res & 14 & Kamble, $S$ & 2019 & $\begin{array}{l}\text { Big data-driven supply chain performance measurement } \\
\text { system: a review and framework for implementation. }\end{array}$ & $\begin{array}{l}\text { Int J Production } \\
\text { Research }\end{array}$ \\
\hline
\end{tabular}

Table 5. Cluster \#6 - Analytic Approach

\begin{tabular}{|c|c|c|c|c|c|c|c|c|c|}
\hline \multicolumn{10}{|c|}{ Cluster \#6 Analytic Approach } \\
\hline \multicolumn{5}{|c|}{ Cited References } & \multicolumn{5}{|c|}{ Citing Articles } \\
\hline Cites & Author & Year & Title & Journal & Coverage(\%) & Author & Year & Title & Journal \\
\hline 5 & $\mathrm{Han}_{1} \mathrm{~J}$ & 2012 & Data mining: concepts and techniques. & Elsevier & 14 & Oztekin, A & 2016 & $\begin{array}{l}\text { A data analytic approach to forecasting daily stock returns } \\
\text { in an emerging market. }\end{array}$ & Eur J Oper Res \\
\hline 4 & Turban, E & 2011 & Decision support and business intelligence systems. & $\begin{array}{c}\text { Pearson Prentice } \\
\text { Hall }\end{array}$ & 13 & Oztekin, A & 2016 & $\begin{array}{l}\text { A hybrid data analytic approach to predict college } \\
\text { graduation status and its determinative factors. }\end{array}$ & $\begin{array}{l}\text { Ind Manag\&Data } \\
\text { Syst }\end{array}$ \\
\hline 4 & Delen, D & 2010 & $\begin{array}{l}\text { A machine learning-based approach to prognostic } \\
\text { analysis of thoracic transplantations. }\end{array}$ & Artif Intell Med & 4 & Chongwatpol, J & 2015 & $\begin{array}{l}\text { Integration of rfid and business analytics for trade show } \\
\text { exhibitors. }\end{array}$ & Eur J Oper Res \\
\hline 3 & $\lfloor u, C J$ & 2010 & $\begin{array}{l}\text { Combining independent component analysis and growing } \\
\text { hierarchical self-organizing maps with support vector } \\
\text { regression in product demand forecasting. }\end{array}$ & Int J Prod Econ & 4 & Chongwatpol, J & 2015 & Prognostic analysis of defects in manufacturing. & $\begin{array}{l}\text { Ind Manag\&Data } \\
\text { Syst }\end{array}$ \\
\hline 3 & Shive, YR & 2009 & $\begin{array}{l}\text { Data-mining-based dynamic dispatching rule selection } \\
\text { mechanism for shop floor control systems using a support } \\
\text { vector machine approach. }\end{array}$ & Int J Prod Res & 3 & Kartal, $\mathrm{H}$ & 2016 & $\begin{array}{l}\text { An integrated decision analytic framework of machine } \\
\text { learning with multi-criteria decision making for multi- } \\
\text { attribute inventory classification. }\end{array}$ & Comp\&lnd Eng \\
\hline
\end{tabular}

\section{B. Key Documents}

As shown in the results of DCA, most of the key documents were steadily published between 2002 and 2018 (see Table 6). Landmark articles are usually the most cited because of the significance of their contribution.
The most cited article is "Big data analytics in logistics and supply chain management: Certain investigations for research and applications" [19] with 186 citations, followed by "The impact of business analytics on supply chain performance" [18] with 133 citations. The third-most-cited article is "Big data analytics: Understanding its capabilities 
and potential benefits for healthcare organizations" [20]. Wang et al. [19] suggested a framework on how to use the benefits of big data suitably with supply chain management and applied big data business analytics to logistics and supply chain management. Trkman et al. [18] conducted an experiment on the influence of business analytics on supply chain management. Wang [20] argued that the usage of big data will generate significant competitiveness because healthcare is related directly with peoples' lives.

Table 6. 15 Key Documents

\begin{tabular}{|c|c|c|c|c|c|}
\hline & Author & Year & Title & Journal & Citation Counts \\
\hline 1 & Wang, $G$ & 2016 & Big data analytics in logistics and supply chain management: Certain investigations for research and applications & IN J OF PRODUCTION ECONOMICS & 186 \\
\hline 2 & Trkman, P & 2010 & The impact of business analytics on supply chain performance & DECISION SUPPORT SYSTEMS & 133 \\
\hline 3 & Wang, YC & 2018 & Big data analytics: Understanding its capabilities and potential benefits for healthcare organizations & TECHN FORECASTING AND SOCIAL CHANGE & 106 \\
\hline 4 & Jourdan, Z & 2008 & Business intelligence: An analysis of the literature & INFORMATION SYSTEMS MANAGEMENT & 105 \\
\hline 5 & Gallino, S & 2014 & Integration of Online and Offline Channels in Retail: The Impact of Sharing Reliable Inventory Availability Information & MANAGEMENT SCIENCE & 100 \\
\hline 6 & Delen, D & 2013 & Data, information and analytics as services & DECISION SUPPORT SYSTEMS & 96 \\
\hline 7 & Kohavi, $\mathrm{R}$ & 2002 & Emerging trends in business analytics & COMMUNICATIONS OF THE ACM & 90 \\
\hline 8 & Akter, $S$ & 2016 & Big data analytics in E-commerce: a systematic review and agenda for future research & ELECTRONIC MARKETS & 89 \\
\hline 9 & Chang, V & 2014 & The Business Intelligence as a Service in the Cloud & THE INT J OF E-SCIENCE & 73 \\
\hline 10 & Holsapple, C & 2014 & \begin{tabular}{|l|l} 
A unified foundation for business analytics \\
\end{tabular} & DECISION SUPPORT SYSTEMS & 73 \\
\hline 11 & Elbashir, MZ & 2011 & The Role of Organizational Absorptive Capacity in Strategic Use of Business Intelligence to Support Integrated Management Control Systems & ACCOUNTING REVIEW & 67 \\
\hline 12 & Tan, TF & 2014 & \begin{tabular}{|l|} 
When Does the Devil Make Work? An Empirical Study of the Impact of Workload on Worker Productivity \\
\end{tabular} & MANAGEMENT SCIENCE & 61 \\
\hline 13 & Tambe, $\mathrm{P}$ & 2014 & Big Data Investment, Skills, and Firm Value & MANAGEMENT SCIENCE & 60 \\
\hline 14 & Kache, F & 2017 & Challenges and opportunities of digital information at the intersection of Big Data Analytics and supply chain management & INT J OF OPER \& PROD MANAG & 50 \\
\hline 15 & Lacity, MC & 2011 & Business process outsourcing studies: a critical review and research directions & J OF INFORMATION TECHNOLOGY & 49 \\
\hline
\end{tabular}

\section{Burst Detection}

Generally, a highly influential document gets its reputation due to the steady accumulation of citation counts. Documents selected by burst detection do not have enough citation counts to be noticed. However, the burst article receives a large number of citation counts during a short period of time. These sudden citation counts result mostly from a newly arranged environment or an incident that occurred during a certain period. The burst detection result of this research is shown in Figure 2.

\section{Top 3 References with the Strongest Citation Bursts}

\begin{tabular}{|c|c|c|}
\hline References & Year Strength Begin End & $2002-2019$ \\
\hline Davenport TH, 2007, CONPETNG ANAL NEW S, VO,PO & 20078.836720112015 & \\
\hline Trkman P, 2010, DECIS SUPPORT STST, V49, P318, DOI & 4.85420132017 & \\
\hline Chen HC, 2012, MS QUART, V36, P1165 & 3.83220162017 & \\
\hline
\end{tabular}

Fig 2. The Result of Burst Detection

The reference with the strongest citation burst is "Competing on analytics: the new science of winning" [9] with 8.8367 , followed by "The impact of business analysis on supply chain performance" [18] with 4.8540. Davenport and Harris [9] proposed that organizations should be superior in analysis in order to have a strong competitive advantage in the market. Because statistics are based on reliable facts to inform a better decision, Davenport and Harris's research seems to have a great impact as a helpful reference to practitioners. Trkman et al. [18] analyzed the impact of business analytics on supply chain management and business performance. As the research on the relationship between business analytics and supply chain management increased, Trkman et al.'s [18] research suddenly began receiving more attention in 2013.

\section{Timeline}

This research analyzed how clusters are separated and connected chronologically. Figure 3 shows the result of timeline analysis based on 18 years (20022019) of data. The red nodes indicate the documents that are detected as bursts and the nodes are the documents that have strong or weak citation counts. Cluster \#0 (In-Memory Analytics) has a majority of strong citation counted documents; however, their impact became weaker in recent times. Cluster \#1 (Supply Chain Disruption Mitigation), Cluster \#2 (Firm Performance), Cluster \#3 (Managing Supply Chain Resource) and Cluster \#4 (Analytics-enabled Decision-making Effective-ness) shows the most active connections until very recently, which can be seen as a rising trend. As the connections between Cluster \#5 (Operational Performance), Cluster \#6 (Analytic Approach), Cluster \#7 (Analytic Discipline), and Cluster \#9 (Interactive Exploration) remain around the year 2010, the effect of these clusters would further decline in the future. 


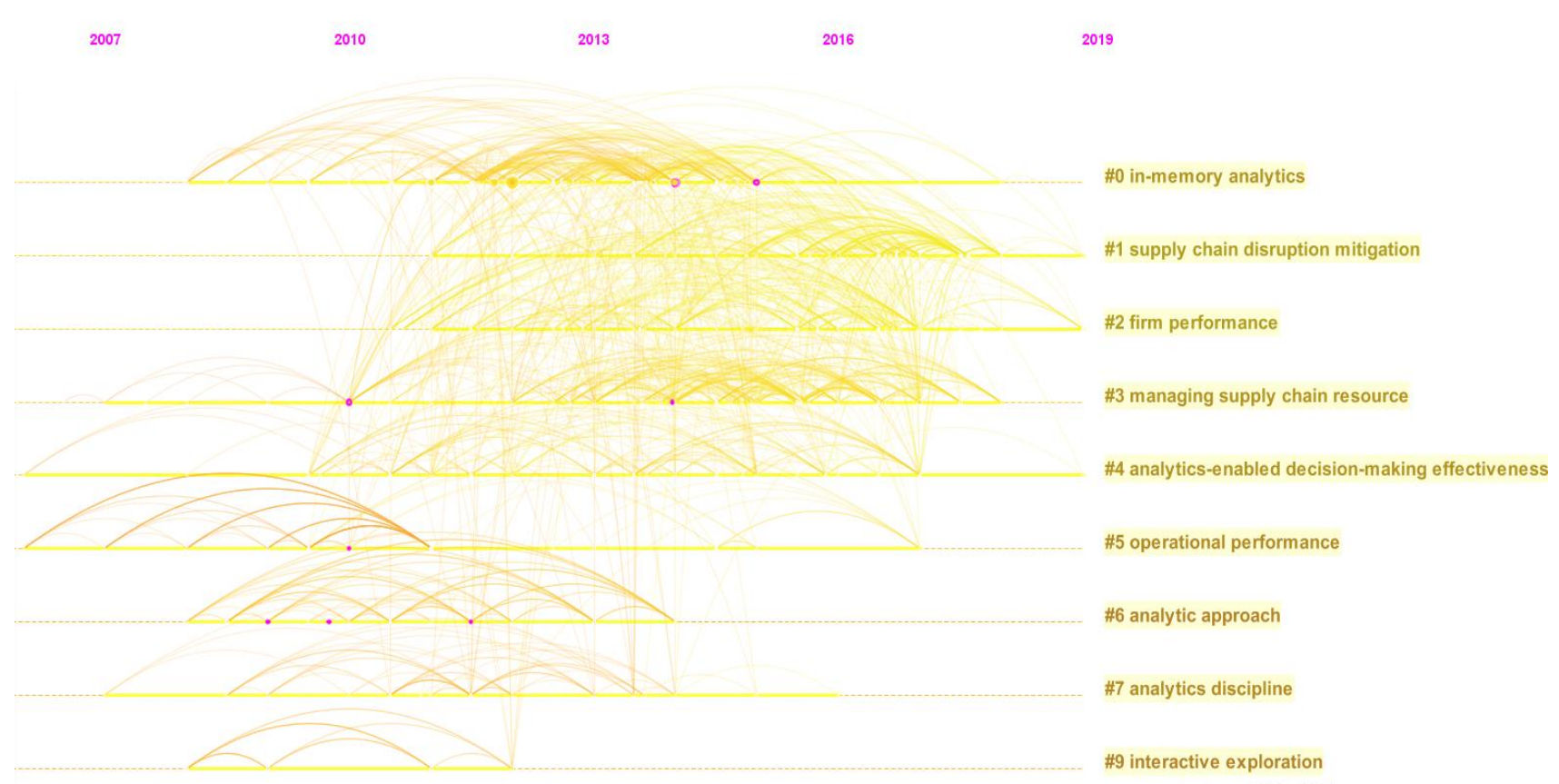

Fig 3. Timeline (2002-2019)

\section{CONCLUSION}

Global companies like Walmart, Amazon, and Netflix have applied business analytics and produced satisfying performances. An enormous number of studies about business analytics have been conducted and the accumulated research is considerable in quantity. This research identifies the intellectual structures of accumulated studies based on business analytics data. The major results of this research can be summarized as follows:

- Three hundred and thirty-three documents about 'business analytics' were extracted from the 'Web of Science' database as data for this research.

- DCA and ACA were conducted using the program CiteSpace.

- A total of nine clusters were shown on the network through cluster analysis. Cluster \#0 (In-Memory Analytics) has the largest and most influencing cluster and Cluster \#9 (Interactive Exploration) the smallest.

- Fifteen key documents were extracted. Supply chain management appears to be the domain most related to business analytics and a rising trend was identified in healthcare.

- Three burst documents were detected.

- Two different groups of clusters were identified: rising clusters (Cluster \#0 through \#5) and declining clusters (Cluster \#6 through \#9).

Understanding the intellectual structure of a domain means that we can predict the future of research because we can visualize the flow of the research domain from the past to the present. Well-performing business analytics is required to have a positive impact on the decision-making process and performance. To do so, researchers and practitioners require a good understanding of business analytics. These are some suggestions for further research.

- We collected the data from the Web of Science only. Extracting a larger amount of data from additional databases might lead to more precise results.

- ACA only considers the first author as data. The elimination of the co-author is a known issue in ACA, an issue that needs to be addressed and improved upon in future research.

- Recent research papers may not have enough cocitation counts in order to check the influence of the factor. However, this limitation is another known issue for review articles.

\section{References:}

[1] Acedo, F. J., Casillas, J. C., Current paradigms in the international management field: An author co-citation analysis, International Business Review, Vol. 14, No. 5, 2005, pp. 619-639.

[2] Akter, S., Wamba, S. F., Gunasekaran, A., Dubey, R., Childe, S. J., How to improve firm performance using big data analytics capability and business strategy alignment?, International Journal of Production Economics, Vol. 182, 2016, pp. 113-131. 
[3] Ashrafi, A., Ravasan, A. Z., Trkman, P., Afshari, $S$., The role of business analytics capabilities in bolstering firms' agility and performance, International Journal of Information Management, Vol. 47, 2019, pp. 1-15.

[4] Brinch, M., Stentoft, J., Jensen, J. K., Rajkumar, C., Practitioners understanding of big data and its applications in supply chain management, International Journal of Logistics Management, Vol. 29, No. 2, 2018, pp. 555-574.

[5] Chen, C., Searching for intellectual turning points: Progressive knowledge domain visualization, Proceedings of the National Academy of Sciences, Vol. 101, No. 1, 2004, pp. 5303-5310.

[6] Chen, C., CiteSpace II: Detecting and visualizing emerging trends and transient patterns in scientific literature, Journal of the American Society for information Science and Technology, Vol. 57, No. 3, 2006, pp. 359-377.

[7] Chen, H., Chiang, R. H., Storey, V. C., Business intelligence and analytics: From big data to big impact, MIS Quarterly, Vol. 36, No. 4, 2012, pp. 1165-1188.

[8] Cui, Y., Mou, J., Liu, Y., Knowledge mapping of social commerce research: A visual analysis using CiteSpace, Electronic Commerce Research, Vol. 18, No. 4, 2018, pp. 837-868.

[9] Davenport T. H., Harris, J. G., Competing on analytics: The new science of winning, Harvard Business Review, Vol. 4, No. 1, 2007, pp. 98.

[10] Feng, F., Zhang, L., Du, Y., Wang, W., Visualization and quantitative study in bibliographic databases: A case in the field of university-industry cooperation, Journal of Informetrics, Vol. 9, No. 1, 2015, pp. 118-134.

[11] Han, J., Pei, J., Kamber, M., Data Mining: Concepts and Techniques, Elsevier, 2011.

[12] Kim, Y. J., Kim, C. H., Mapping the intellectual structure of communication research field in Korea: An author co-citation analysis, 19892006, Journal of Korean Communications, Vol. 15, No. 3, 2007, pp. 155-184.

[13] Lee, M. O., Major themes and trends in Korea women's Studies: The results of author cocitation analysis, Korea Association of Women's Studies, Vol. 12, No. 1, 1996, pp. 180-203.

[14] Li, X., Ma, E., Qu, H., Knowledge mapping of hospitality research - A visual analysis using CiteSpace, International Journal of Hospitality Management, Vol.60, 2017, pp. 77-93.

[15] Lin, Z., Wu, C., Hong, W., Visualization analysis of ecological assets/values research by knowledge mapping, Acta Ecologica Sinica, Vol. 35, No. 5, 2015, pp. 142-154.
[16] Oztekin, A., Kizilaslan, R., Freund, S., Iseri, A., A data analytic approach to forecasting daily stock returns in an emerging market, European Journal of Operational Research, Vol. 253, No. 3, 2016, pp. 697-710.

[17] Shiau, W. L., Chen, S. Y., Tsai, Y. C., Management information systems issues: cocitation analysis of journal articles, International Journal of Electronic Commerce Studies, Vol. 6, No. 1, 2015, pp. 145-162.

[18] Trkman, P., McCormack, K., De Oliveira, M. P. V., Ladeira, M. B., The impact of business analytics on supply chain performance, Decision Support Systems, Vol. 49, No. 3, 2010, pp. 318327.

[19] Wang, G., Gunasekaran, A., Ngai, E. W., Papadopoulos, T., Big data analytics in logistics and supply chain management: Certain investigations for research and applications, International Journal of Production Economics, Vol. 176, 2016, pp. 98-110.

[20] Wang, G., Big data analytics: Understanding its capabilities and potential benefits for healthcare organization, Technological Forecasting and Social Change, Vol. 126, 2018, pp. 3-13.

[21] White, H. D., Griffith, B. C., Author cocitation: A literature measure of intellectual structure, Journal of the American Society for information Science, Vol. 32, No. 3, 1981, pp. 163-171.

[22] Yu, D., Xu, Z., Pedrycz, W., Wang, W., Information sciences 1968-2016: A retrospective analysis with text mining and bibliometric, Information Sciences, Vol. 424, 2017, pp. 619-634.

[23] Zhang, X., Gao, Y., Yan, X., de Pablos, P. O., Sun, Y., Cao, X., From E-learning to sociallearning: Mapping development of studies on social media-supported knowledge management, Computers in Human Behavior, Vol. 51, 2015, pp. 803-811.

\section{Creative Commons Attribution License 4.0 (Attribution 4.0 International, CC BY 4.0)}

This article is published under the terms of the Creative Commons Attribution License 4.0 https://creativecommons.org/licenses/by/4.0/deed.en US 